ISSN 1112-9867

http://www.jfas.info

\title{
EFFECT OF GEM PEHD THERMAL PROPERTIES ON THE PROPAGATION OF HEAT IN SOLAR STILLS
}

\author{
N. Baba Ahmed ${ }^{1, *}$, A. Benmoussat ${ }^{2}$ and K. Aliane $^{1}$ \\ ${ }^{1}$ Department of Physique, Faculty of Science, Abou Bekr Belkaïd University of Tlemcen, 22 \\ rue Abi Ayed Abdelkrim Faubourg Pasteur B.P 11913000 Tlemcen, Algeria \\ ${ }^{2}$ Materials sciences and Environment Group, Faculty of sciences and Technology, Department \\ of matter sciences, Tamanrasset University center, BP 10034 SERSOUF, Tamanrasset,
} Algeria

Received: 05 March 2016 / Accepted: 17 August 2016 / Published online: 01 Septembre 2016

\begin{abstract}
The properties of GEM $\mathrm{PEHD}_{\mathrm{P}}$ as an absorber material in a prototype of solar still have been investigated in a temperature range from $300 \mathrm{~K}$ to $400 \mathrm{~K}$. Results showed a dependency between temperature and its properties. The enegy absorbed by the GEM $\mathrm{PEHD}_{\text {increases its }}$ temperature, the power received by the air and the air temperature. Overall losses increase with the difference of the temperature between the GEMPEHD and windows. This increases the efficiency of the solar still and minimizes the entropy of the system. The study of thermal

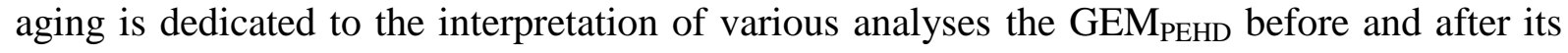

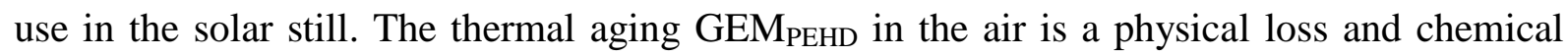
consumption immediately followed by a brutal oxidation of the polymer. The losses would be governed primarily by the chemical consumption of antioxidants.
\end{abstract}

Keywords: GEM ${ }_{\mathrm{PEHD}}$, temperature, solar collector, aging.

Author Correspondence, e-mail: nassimbaba@yahoo.fr

doi: http://dx.doi.org/10.4314/jfas.v8i3.4 


\section{INTRODUCTION}

The motivation of this work focuses on the following findings: An environmental statement to limit the intensity of the greenhouse effect and rising temperatures on the surface of the planet by which action plans for emission limitation some greenhouse gases have been implemented by many countries. An energy finding where energy needs are growing throughout the four corners of the planet. The industrial sector [1] remains the main consumer of energy and the residential and commercial sectors consume mainly because of space heating and coins. The production and consumption of energy contribute to the change in thermal equilibrium at the surface of the earth by producing greenhouse gases that are assigned the current warming of the planet. The thermal pollution also complemented by a physical or chemical waste pollution [2]. Reducing consumption is the most effective way to not only save energy but also reduce pollution. One avenue being explored is to search and use of new energy efficient and clean technologies, which lead to either the depletion of resources or the changes in the environment and enable sustainable development. It should therefore be limited and more effective use of energy, and turn to renewable energy sources. These energies are inexhaustible and severely limit pollution by reducing $\mathrm{CO}_{2}$ emissions. The development of new behaviours and alternative energy is essential. One of the problems in solar capture is the choice of materials and their selectivity to optimize absorption and reduce heat transfer through the insulation or transparent materials to reduce reflections and get the maximum radiation converts. Some materials are on the border between the mechanical and physical applications, such as polymer materials that have seen increasing use in various fields because of their ease of implementation, low cost of production and their mechanical characteristics (hardness, ductility, elasticity, and rigidity). Understanding and predicting the durability of these materials from their degradation are less advanced and disparate depending on how aging (chemical, physical, thermal, and oxidation) $[3,4,5]$. The materials used in solar collectors are characterized by more instability in the slower vis-à-vis time solar radiation. Weathering polymers causes changes in material properties both mechanically, chemically, and morphologically. It combines the effects of light, temperature and oxygen. One of problems in solar capture is the choice of materials and their selectivity to optimize absorption 
and reduce heat transfer through the insulation or transparent materials to reduce reflections and get the maximum radiation converts. We are interested in this study to the polymer material, the high-density polyethylene geomembrane $\left(\mathrm{GEM}_{\mathrm{PEHD}}\right)$ used as a heat absorber in the solar still energy study that will form during sun exposure. Then, we study the influence of aging on the sustainability and efficiency of the solar still. We use various experimental techniques for physicochemical characterization as well as aging of the samples GEM $_{\text {PEHD }}$ to assess the structural and textural properties of our material. In addition, we will present the nonlinear equation modeling of unsteady heat.

\section{MATERIALS AND METHODS}

\subsection{Study material}

GEM $_{\text {PEHD }}$, study polymer material, is provided by CHIALI Company in Algeria as granules stabilized with antioxidants and process the nature of which has not been specified us. This polymer corresponds to the basic matrix of a commercial GEM. The PE100: PEHD was added $0.4 \%$ by weight of a phenolic antioxidant, Irganox B225. Material has endured aging accelerates high temperature in a ventilated oven in air at atmospheric pressure in order to follow the structural evolution during the period of exposure in the solar still.

\subsection{Solar still}

The test bench was performed at Tlemcen - Algeria with latitude 35.28 degrees, a longitude of $-1.17^{\circ}$ and an altitude of $750 \mathrm{~m}$. It is characterized by lots of sunshine, with an average daily irradiation $6000 \mathrm{Wh} / \mathrm{m}^{2}$, a sunshine duration of 3000 hours a year and a clearness index $\mathrm{K}_{\mathrm{t}}$ average of 0.75 [6]. The prototype of solar still is shown in Figure 1. The total area is $2.6 \mathrm{~m}^{2}$, and the opening area equal to $2.4 \mathrm{~m}^{2}$. It is mounted on a rigid adjustable steel structure with a $45^{\circ}$ inclination. The solar still is a parallelepiped shape, constructed with galvanized sheet metal (thickness e $=1.5 \mathrm{~mm}$, length $\mathrm{L}=1 \mathrm{~m}$, width $=0.2 \mathrm{~m}$ ). It is internally reinforced by angle irons, covered outside by wooden cork as a thermal insulator between two glass wool layer of $5 \mathrm{~cm}$ thickness on the side surfaces and on the rear surface. Inside the metal sheet is covered by GEM $_{\text {PEHD }}$ as a heat absorber with $5 \mathrm{~mm}$ of thickness. Two sheet metal of $4 \mathrm{~mm}$ thick, form the transparent cover each with a space between two panes of $1.5 \mathrm{~cm}$ as 
recommended in the literature [7] because this minimizes the edge effect while maintaining low loss by convection. In this study, we are interested in the front part of the solar still, the heat from the solar rays that pass through the glass and are absorbed by the inner face of the wall placed on the absorber. The lower face is subjected to a constant heat flux simulating the energy received by the solar radiation on a face of negligible thickness [8].

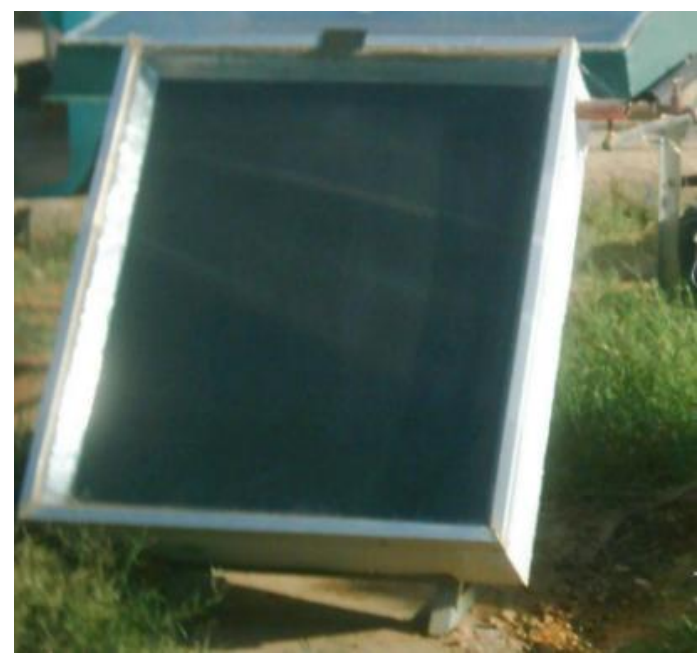

Fig.1. Solar still

\subsection{Material characterization}

Some intrinsic properties of the GEM PEHD $_{\text {are given in Table } 1 .}$

Table 1. Intrinsic properties of the GEMPEHD

\begin{tabular}{|c|c|c|}
\hline Properties & Unit & Value \\
\hline Volumes density $\rho_{P E}$ & g.cm ${ }^{-3}$ & $0,974 \pm 0,01$ \\
\hline Thermal conductivity $k_{P E}$ & $W / m \cdot K$ & $0,28 \pm 0,01$ \\
\hline Thermal diffusivity $a_{P E}$ & $\mathrm{~m}^{2} / \mathrm{s}$ & $(0,314 \pm 0,02) \cdot 10^{-6}$ \\
\hline Density $^{*}$ & $\mathrm{~g} / \mathrm{cm}$ & $0,949 \pm 0,001$ \\
\hline Temperature of fusion ${ }^{* *}$ & ${ }^{\circ} \mathrm{C}$ & $135,7 \pm 0,1$ \\
\hline Degree of crystallinity $^{* *}$ & $\%$ & $78 \pm 2$ \\
\hline Weight average molar mass ${ }^{* * *}$ & $\mathrm{~g} / \mathrm{mol}$ & $500,4 \pm 0,4$ \\
\hline Glass transition temperature & ${ }^{\circ} \mathrm{C}$ & -125 \\
\hline Coefficient of expansion & $\mathrm{C}^{-1}$ & $19 \cdot 10^{-5}$ \\
\hline
\end{tabular}

* Measured by a weighing device on a Mettler TOLEDO in air and in acetone.

** Measured by differential scanning calorimetry with a temperature rise rate of $10^{\circ}$ C.min- 1 in an inert atmosphere.

*** Measured by steric exclusion chromatography at $145^{\circ} \mathrm{C}$ in $1,2,4$ trichlorobenzene with a chromatographic 
system equipped with a triple detection (Viscometer, refractive index and Laser).

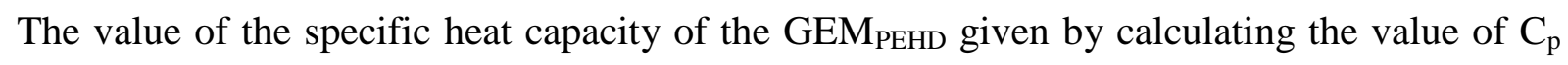
from the values of measured density, conductivity and thermal diffusivity using the following relationship:

$$
C_{P}=\frac{k}{a \cdot \rho}
$$

The value of the following specific heat capacity is $C_{P_{P E}}=(2300 \pm 0,012) \mathrm{J} / \mathrm{Kg} \cdot \mathrm{K}$.

Spectral emissivity remains measured at room temperature, approximately $20{ }^{\circ} \mathrm{C}$. The results illustrated in Figure 2. This figure shows that the emissivity varies little within this range of temperatures and wavelengths. Figure 3 shows that the emissivity of the GEMPEHD reaches a constant value for a sample of thickness greater than $0.2 \mathrm{~mm}$. We find the value 0.93 determined above. Beyond this thickness, GEM $_{\text {PEHD }}$ may considered opaque with respect to the IR radiation.

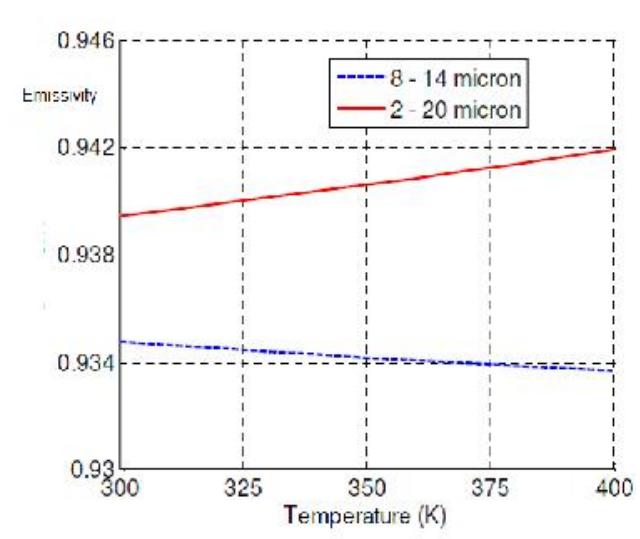

Fig. 2. emissivity of the GEMPEHD

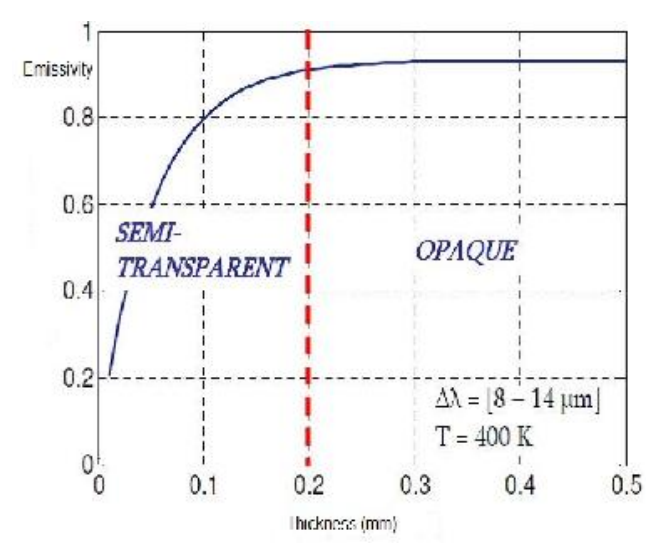

Fig. 3. Total emissivity of GEM PEHD

The method allows the measurement of the hemispherical directional reflectivity and there after calculate the emissivity of the surface using a portable emissometer $[9,10,11,12]$. The current equipment design for easy use in the field and better to control of the operation of the infrared source; it allows achieving emissivity measurements in different wavelength bands that the optical detector can be replaced very easily. The method chosen for the characterization of the density is that of the pycnometer. The measurements made with a

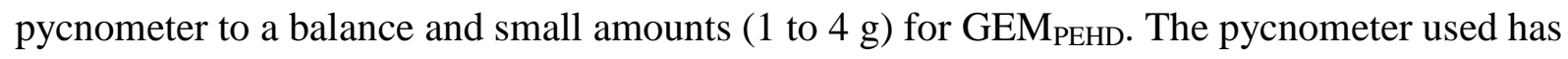
a marked capillary to measure a precise volume. Thermal Conductivity and Thermal 
diffusivity: We propose a measuring method enabling the simultaneous characterization of the thermal conductivity (k) and thermal diffusivity (a) a sample of the GEM $\mathrm{PEHD}_{\mathrm{P}}$ at room temperature [13]. We modulate the temperature of the sample and measure the temperature variations on each of its faces. The measurements performed under vacuum (pressure $<10^{-4}$ mbar) to reduce convection losses on the sides. ATG thermal analysis of samples conducted used is of type SDT Q600. The analysis performed in air with a temperature ramp of $5{ }^{\circ} \mathrm{C} /$ min in the range of 25 to $1200{ }^{\circ} \mathrm{C}$ for a few samples at $1000{ }^{\circ} \mathrm{C}$ for others. Differential scanning calorimetry performed on a Perkin Elmer Lambda 800 flown from a microcomputer. Infrared analysis in Fourier transform (FTIR) was performed using an Avatar 320 FTIR spectrometer THERMO-NICOLET. Spectra were recorded either transmittance (T) or absorbance (A) between $4000 \mathrm{~cm}^{-1}$ and $400 \mathrm{~cm}^{-1}$. The X-ray diffraction (DRX) performed with a PANalytical X'Pert diffractometer type Pro goniometer with a theta / theta.

\section{MODELLING AND SIMULATION}

The process of the solar collector includes heat transfer of different kinds [14]. The radiative transfer course plays a predominant role in the infrared heating phase. The convective heat transfer, resulting from the temperature difference between the absorber and the glazing ambient air, in turn play a major role in particular during the cooling phase. Finally, thermal gradients generated by the two types of transfers are at the origin of conduction transfers within the solar still. During the thermal treatment, these three types of heat exchange are coupled, and transient. We identified the main problems associated with the modelling of each type of heat transfer. We now turn to mathematical modelling aspects of these heat transfers. Recall that the main objective of this modelling is to predict the temperature distribution of the GEM $\mathrm{PEHD}_{\mathrm{P}}$ following its thermal conditioning. The evolution of the temperature at a point

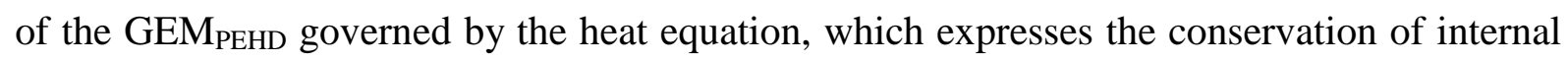
energy of a system:

$$
\lambda(T) \cdot \nabla^{2} T+\frac{d \lambda(T)}{d T} \cdot|\operatorname{grad} T|^{2}=\gamma(T) \cdot \frac{\partial T}{\partial t}-\left(\frac{K \cdot \sigma}{\pi}\right)^{2} \cdot \frac{[\varepsilon(T)]^{2}}{\rho(T)} \cdot T^{8}
$$


Where $\mathrm{T}$ is the temperature, $\rho(T), \gamma(T), \lambda(T)$ and $\varepsilon(T)$ are respectively the density, the specific heat capacity, thermal conductivity and emissivity of the GEM PEHD. $_{\text {. }}$

The radiant flux density is a function of the emissivity. Finally, the conductive flux density connected to the temperature gradient according to the Fourier law. As we mentioned above, the convective transfers surface. They do not explicitly involved in the heat equation. However, they can addressed through a requirement to Fourier-type limits. The boundary conditions are:

$$
\begin{aligned}
& \left.T\right|_{x=0}=304.15+274.85 \cdot \cos (0.05 \cdot \pi \cdot t) \\
& -\left.\lambda_{0} \frac{\partial T}{\partial x}\right|_{x=x_{0}}=h_{c} \cdot\left(T_{x_{0}}-T_{\infty}\right)+\varepsilon_{G E M_{\text {PEHD }}} \cdot \sigma \cdot\left(T_{x_{0}}^{4}-T_{\infty}^{4}\right)
\end{aligned}
$$

Where $h_{\mathrm{c}}$ is the convective heat transfer coefficient, $\sigma$ Stefan-Boltzmann constant $(\sigma=5.67$ $10^{-8} \mathrm{Wm}^{-2} \cdot \mathrm{K}^{-4}$ ), designates the outer surface temperature of the GEM $\mathrm{PEHD}_{\infty}, \mathrm{T}_{\infty}$ temperature of ambient air and the emissivity average GEM ${ }_{\text {PEHD. }}$

$$
\begin{array}{ll|l}
\lambda(T)=\lambda_{0} \cdot\left(1+\alpha^{\prime} \cdot T\right) & \lambda_{0}=0,28 \ldots W \cdot m^{-1} \cdot K^{-1} & t_{0}=7200 \ldots \text { secondes } \\
\rho_{0}=6.9 \cdot 10^{-8} \ldots \text { Ohm } \cdot m \\
\gamma(T)=\gamma_{0} \cdot(1+\beta \cdot T) & c_{0}=2300 \ldots J \cdot K^{-1} \cdot K & \alpha=4.47761 \cdot 10^{-4} \ldots K^{-1} \\
\rho(T)=\rho_{0} \cdot(1+\alpha \cdot T) & \delta_{0}=0,949 \ldots K g \cdot m^{-1} & \alpha^{\prime}=-12.021276 \cdot 10^{-4} \ldots K^{-1} \\
\varepsilon(T)=1,35 \cdot \sqrt{\rho(T) \cdot T}-0,017 & x_{0}=1 \ldots m & \beta=5.88235 \cdot 10^{-4} \ldots K^{-1}
\end{array}
$$

The Convective transfer between the outer surface of the GEM $_{\mathrm{PEHD}}$ and the air is natural type. The average convective exchange coefficient can be estimated using the correlation Churchill and Chu [15] established for a flow around a vertical plate in natural convection:

$$
h_{c}=\frac{\lambda_{0}}{L}\left[0,825+\left(0,387 \cdot R a^{\frac{1}{6}}\right) /\left(1+\left(0,492 / \operatorname{Pr}^{\frac{9}{16}}\right)^{\frac{8}{27}}\right)\right]^{2} \text { avec } R a \leq 10^{9}
$$

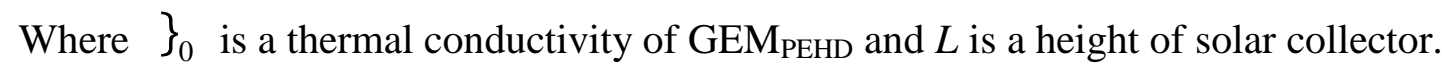

The dimensionless numbers Ra and Pr denote the number of Rayleigh and Prandtl [16]. Note that this correlation is only valid if the Rayleigh number is below 109, which is the case in our study as shown in Table 2. 
Table 2. Number of Prandtl and Rayleigh to different temperatures GEMPEHD

\begin{tabular}{ccc}
\hline temperature $\left({ }^{\circ} \mathbf{C}\right)$ & Pr & Ra \\
\hline 20 & 0,690 & 0 \\
\hline 60 & 0,689 & $1,0510^{6}$ \\
\hline 100 & 0,688 & $1,610^{6}$ \\
\hline
\end{tabular}

These results take into account the variation of the physical and thermal properties of air as a function of temperature. The calculation of dimensional numbers carried out at the

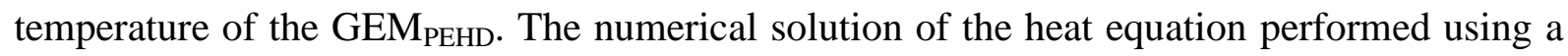
finite volume discretization in three dimensions. This method is to mesh the solar sensor control volumes, and integrate the heat equation (1) on each volume element, and the time between time $\mathrm{t}$ and time $t+t$. The calculation conducted using a computer code using the finite volume method, which describes the geometry of the mesh and the problem to be treated and the type of boundary conditions.

\section{RESULTS AND DISCUSSION}

\subsection{Energy study on the solar collector}

The figure 4 gives us the intensity of the solar flux for the four days that are respectively 17 January, 15 May, 16 August and 15 October 2015. It noted that the intensity of the solar flux is greater in the days of May 15 and August 16 in which the days are longer. To see the effect of climatic parameters on changes in air temperature $T_{F}$, weather data was used (direct radiation, wind speed and ambient temperature) measured by the meteorological station in Tlemcen site for day of 16 August. We introduced the values measured in the simulating program of the $\mathrm{T}_{\mathrm{F}}$ area, to see the differences compared to the values obtained by semi-empirical models. 


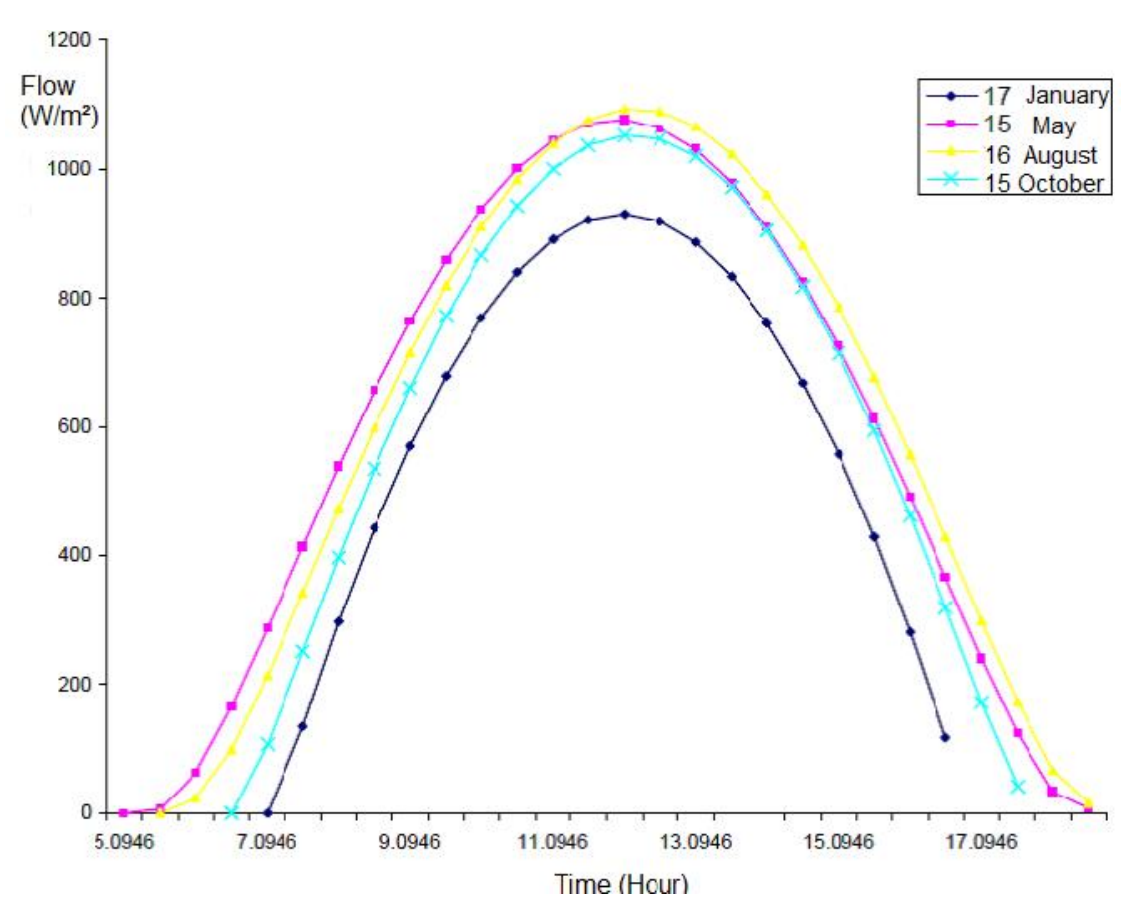

Fig.4. Solar flux for a typical day with very clear sky

These data was shown in Figures 5 and 6. It noted that the numerically values obtained are close to those of the experimental data, the effect of wind speed and room temperature is negligible.

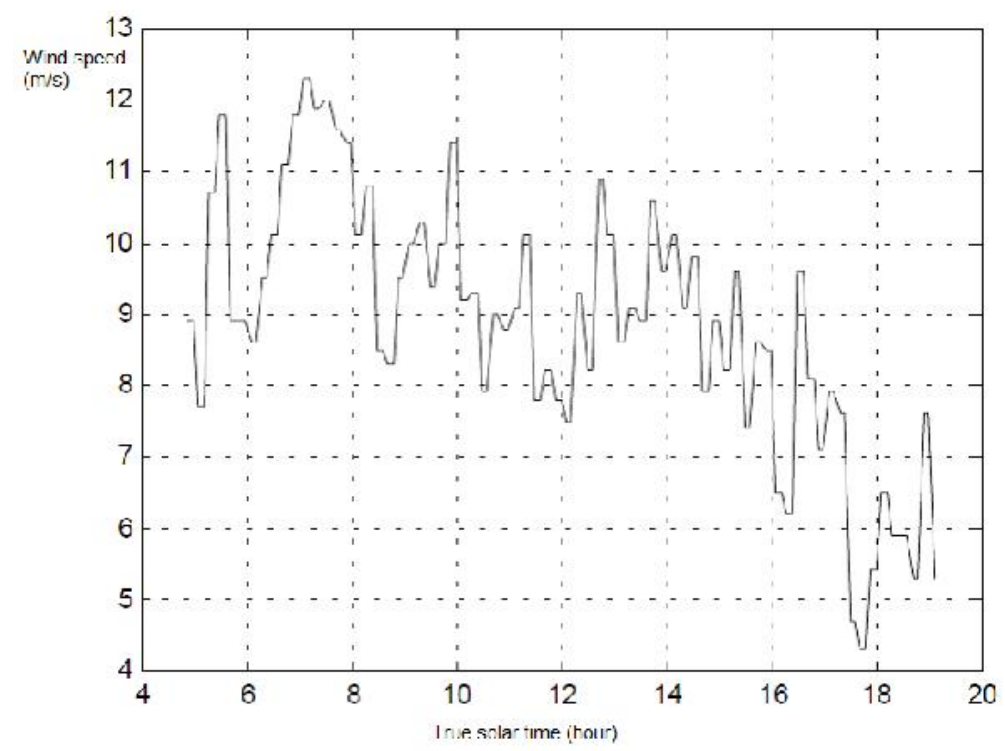

Fig.5. Experimental measurements of wind speed for August 16, 2015 


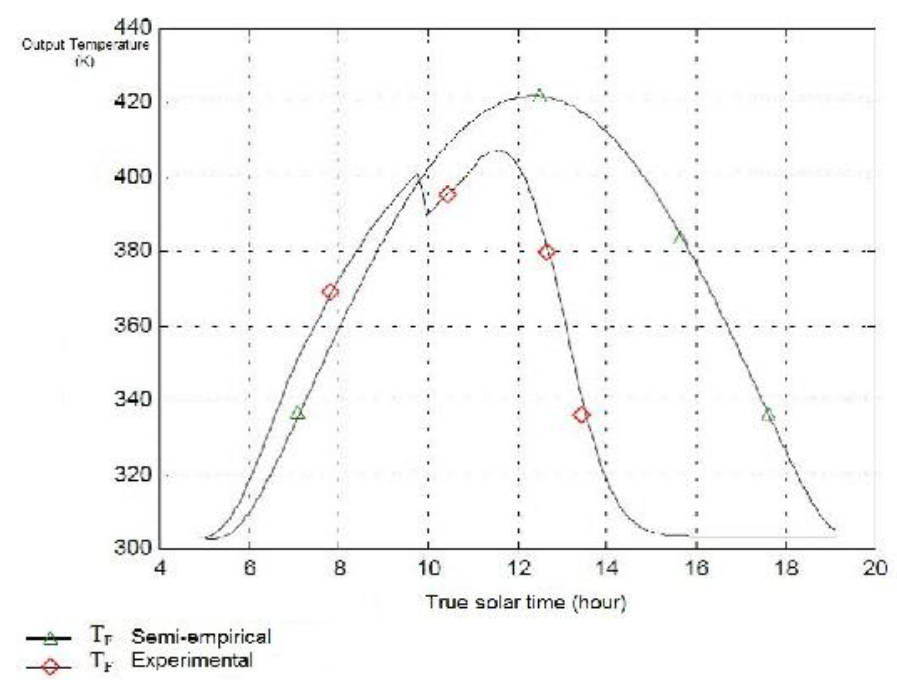

Fig.6. Simulation of the air outlet temperature for 16 August 2015

In the range of airflow values studied from 20 to $200 \mathrm{~kg} / \mathrm{h}$, figure 7 shows the experimental values from previous work $[17,18]$ and are very close to this configuration, in order to validate our digital approach. We note that the experimental values of the instantaneous thermal efficiency of the solar still are not very far from the values from the theoretical models. For low flows, the model overestimates the performance. We believe that this discrepancy can explained on one hand by measurement errors but by theoretical approaches made at the equated the theoretical model are the underestimation of losses in the theoretical model amounted for low airflow rates, because of the higher temperature difference between the absorber and the outside. We could introduce empirical correction coefficient of overall losses, from experimental data, as was done in $[19,20]$.

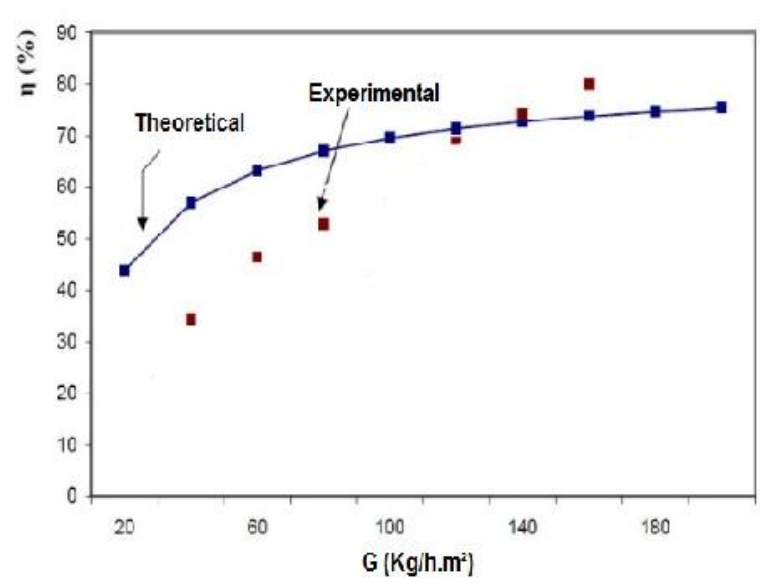

Fig.7. Thermal efficiency of the solar still as a function of air flow

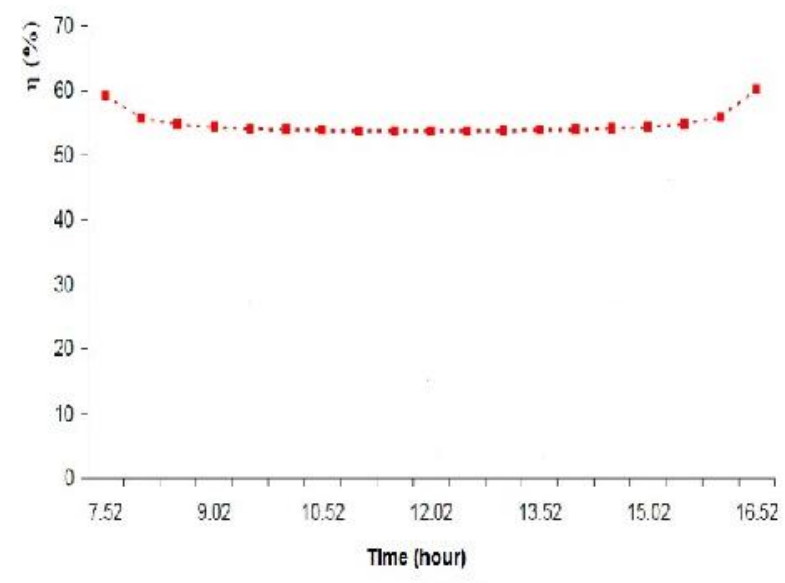

Fig.8. Thermal efficiency of the solar still with a clear sky and a throughput of $35 \mathrm{~kg} / \mathrm{h}$. 
In this work, the evolution of the overall losses $U_{L}$ coefficient was plotted against the temperature difference $\left(\mathrm{T}_{\mathrm{f}}-\mathrm{T}_{\mathrm{a}}\right)$ which is all the more important that the flow rate is low, $\mathrm{T}_{\mathrm{f}}$ being the average air temperature within the air gap and the ambient temperature $T_{a}$. The proposed equation is of the form $U_{L}=a\left(T_{f}-T_{a}\right)^{b}$. The evolution of the instantaneous thermal efficiency of the solar still was shown in Figure 8. We note that the addition of GEM $\mathrm{PEHD}_{\mathrm{P}}$ absorber made a remarkable increase is about $25 \%$ relative to a solar still with another type absorber. Analysis of the various results obtained show that while the duration of the capture of solar radiation near room temperature, the solar still has a good performance, which is around $55 \%$. This performance explained by lower optical and thermal losses through the glazing system. Taking into account the means of realization of our system, its simplicity and its cost price is quite low and compared to other more sophisticated solar still performance found in the literature, we can conclude that our prototype is still competitive with a quality / price very valuable. Based on experimental tests on our system and the different results obtained, we find that more solar illumination is perpendicular to the greater the amount of heat absorbed collecting area is considerable, because the glazing transitivity and absorptivity of the absorbing plate are inversely proportional to the angle of incidence of solar radiation. It is therefore very important to choose the inclination of the solar still with the seasons to take better advantage of the system.

As regards the development of in and out air temperatures, the results confronted with experimentally provides those delivered digitally. Figure 9 shows the temporal variation of the temperature of each sensor element. In this figure, the absorber and the inner surface of the insulator have higher temperatures, this is due to the power absorbed by the absorber is important and is greater than that absorbed by the glass, and the insulation is placed beneath the absorber plate, the latter has a high thermal conductivity. 


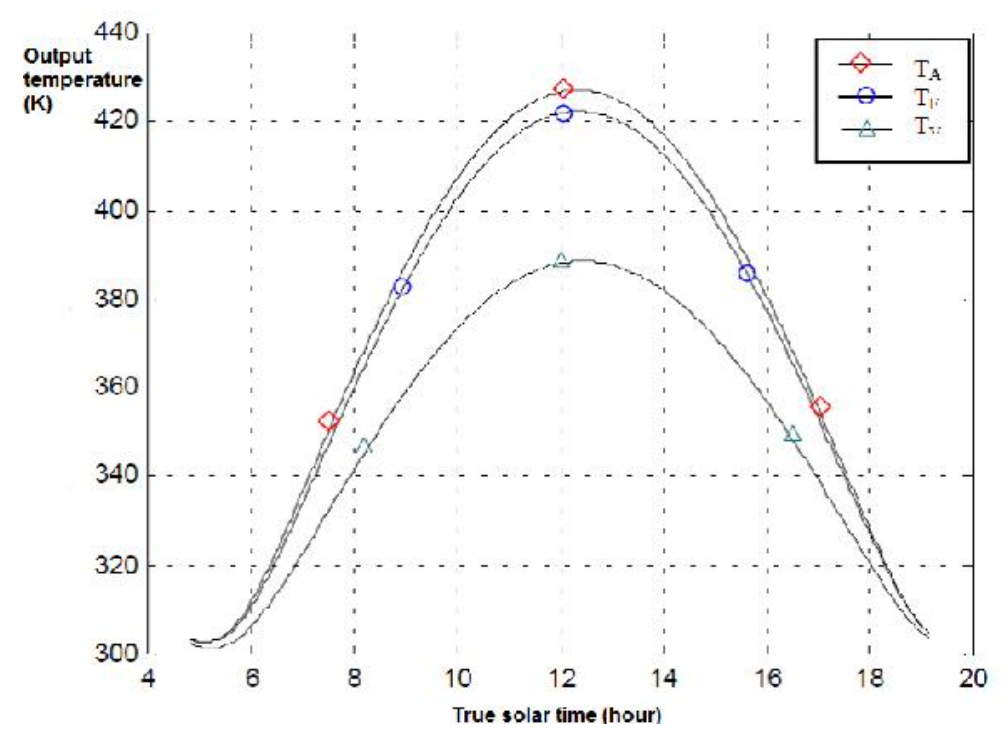

Fig.9. Change in temperature of each element of the solar collector.

The lowest temperature is that of the insulation of the rear side, indicating that the insulation has low thermal conductivity. The increase in indoor and outdoor temperatures glazing is due to absorption by the window of the incident solar radiation and the heat released by the absorber. The temperature of the inner surface is slightly greater than that of the outer face; this is due to the trapping of solar infrared ray inside the sensor thereby increasing the temperature inside of the glass with respect to outside, which assigned to the action of wind. The coolant outlet temperature is slightly lower than that of the absorber, due to losses. On the other hand, the analysis results successively shows good agreement between the results provided by the model and those found in the literature. It is reported that due to the existing deviations from the experimental and theoretical work cited, compared with those of our modeling, are due to the aging phenomenon of the constituent elements the solar still when it comes to enter the corresponding values thermophysical and optical parameters, on the other hand the illuminations seem unfitted models considered under specific conditions.

\subsection{Study of aging GEMPEHD}

Infrared spectroscopy is the first additional technique that we used. A test campaign showed different behavior during the first hours of irradiation. This difference is a greater amount of carbonyls present in the samples prior to irradiation and for other campaigns. The amount of 
vinyl product remains the same as for other campaigns, and has a similar evolution during irradiation, with two separate steps before and after $6 \mathrm{~h}$ of irradiation (Figure 10).

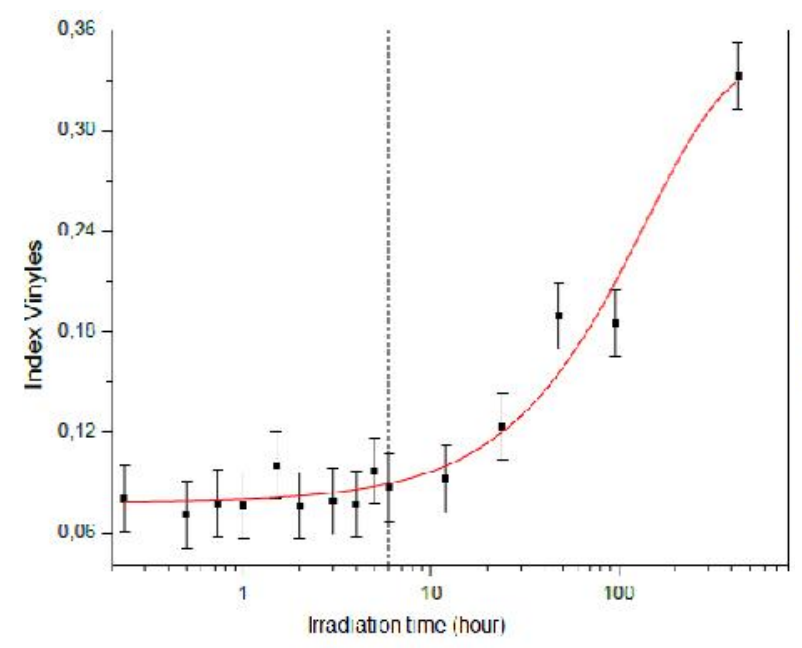

Fig. 10. Vinyl degradation products evolution as a function of UV irradiation time.

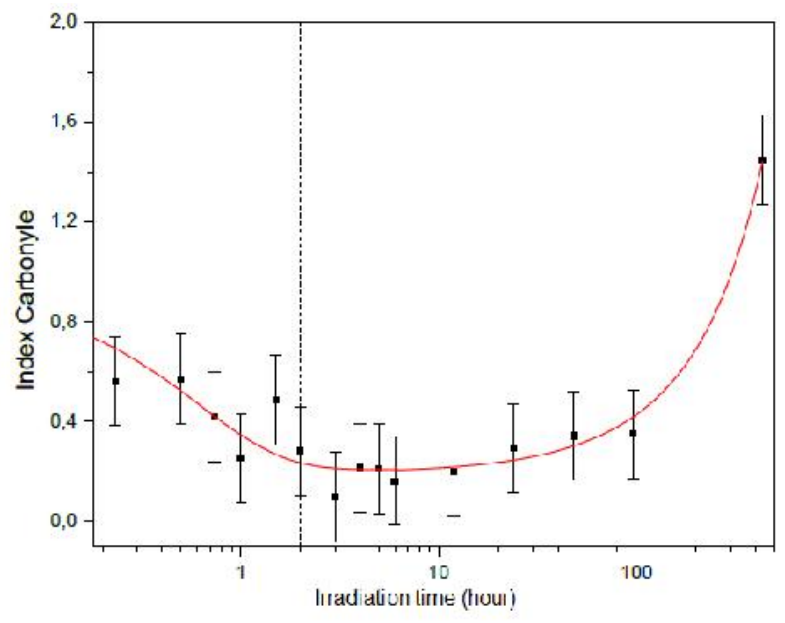

Fig. 11. Evolution of carbonyl degradation products as a function of UV irradiation time.

A presence of strong carbonyl degradation was product an irradiation from the manufacturing protocol. Shaping done on a hot plate at a temperature of $150{ }^{\circ} \mathrm{C}$, to which the $\mathrm{GEM}_{\mathrm{PEHD}}$ undergoes a major thermal oxidation, which causes formation of carbonyl-type degradation products if the exposure time is too long [21, 22]. We chose to keep this trial campaign since the first moments of exposure to UV show interesting behavior (Figure 11).

The differential scanning calorimeter used in the following part will allow us to have access to this information. This technique allows us to obtain information on physical samples and especially the degree of crystallinity $(\% \mathrm{Cr})$ and the melting temperature $\left(\mathrm{T}_{\mathrm{f}}\right)$. Figure 12 shows the change in the rate of crystallinity of the samples according to the UV ray exposure time. As in the case of the infrared spectroscopy analysis, two distinct phases can be observed. Crystallinity rate remains stable at around $72 \%$ during the first 6 hours, then increases exponentially in the semi logarithmic representation to reach the value of $79 \%$ after 18 days of irradiation. 


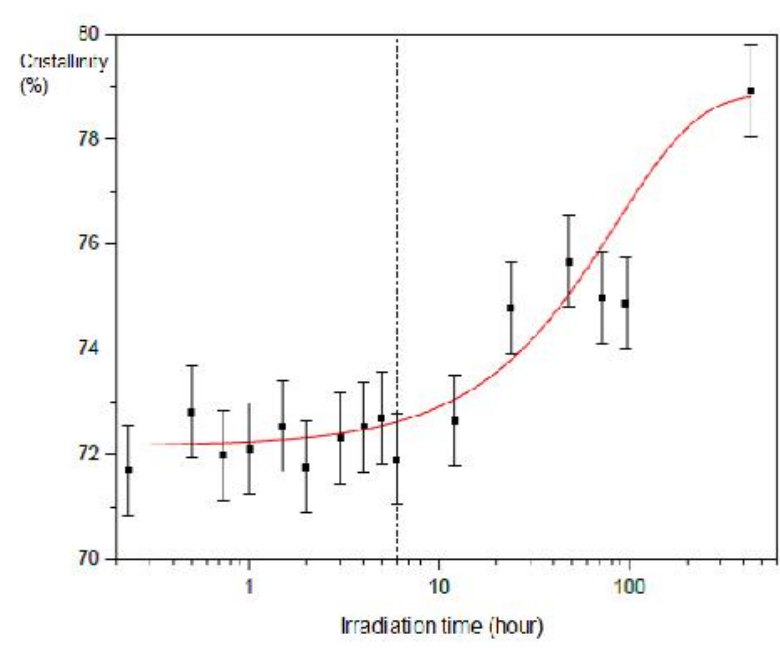

Fig.12. Evolution of the crystallinity during the UV irradiation.

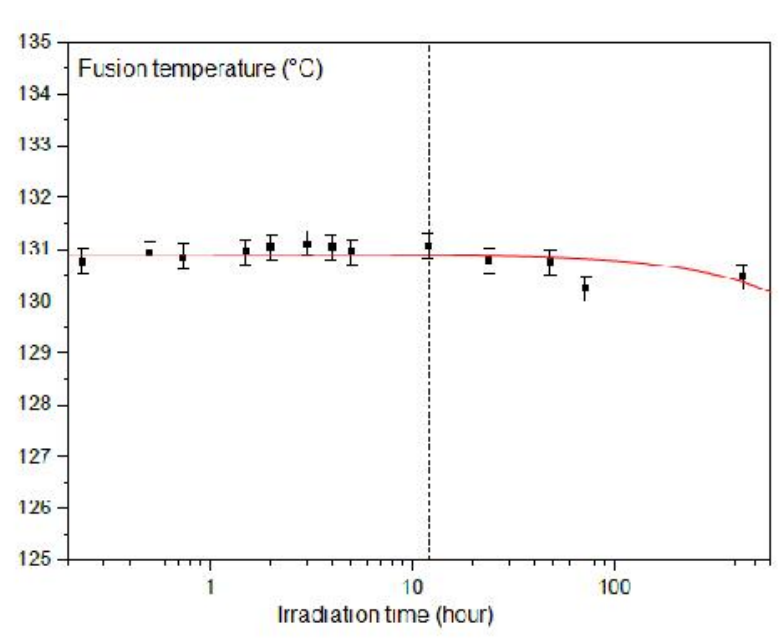

Fig.13. Evolution of the melting temperature of the samples as a function of UV irradiation.

This increase in the degree of crystallinity was accompanied by a slight decrease in the melting temperature (Figure 13). In the literature, different authors interpret these results by changing the macromolecular chains of GEM $_{\mathrm{PEHD}}$ due to UV irradiation. UV radiation causes breaks chains with consequent increases in crystallinity $[23,24]$. In the amorphous phase, chains see their length reduced, making them more mobile [25] and thus favoring the phenomenon called secondary crystallization [26], illustrated here by increasing the degree of crystallinity after $6 \mathrm{~h}$ of exhibition.

From the melting temperature values and crystallinity, it is possible to calculate the size of the crystal lamellae. Preliminary calculations performed on irradiated samples led to size strips of the order of $30.1 \mathrm{~nm}$. The evolution of this value during the deterioration (Figure 14) may also be presented in two stages, in the first moments with a stability followed by a decrease. This development is in line with the first results of degree of crystallinity and melting temperature. The rupture of the macromolecular chains caused by UV radiation leading to lamellae smaller dimensions which plays on the melting temperature and the crystallinity. However, even if all the results obtained in AED are well in line with the already established models.

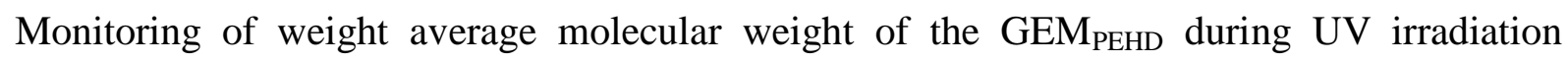
performed by GPC and shows a rapid increase of from an hour of exposure (Figure 15). These results are consistent with an increase in the average length of the macromolecular chains, which can be attributed to cross-linking phenomena. 


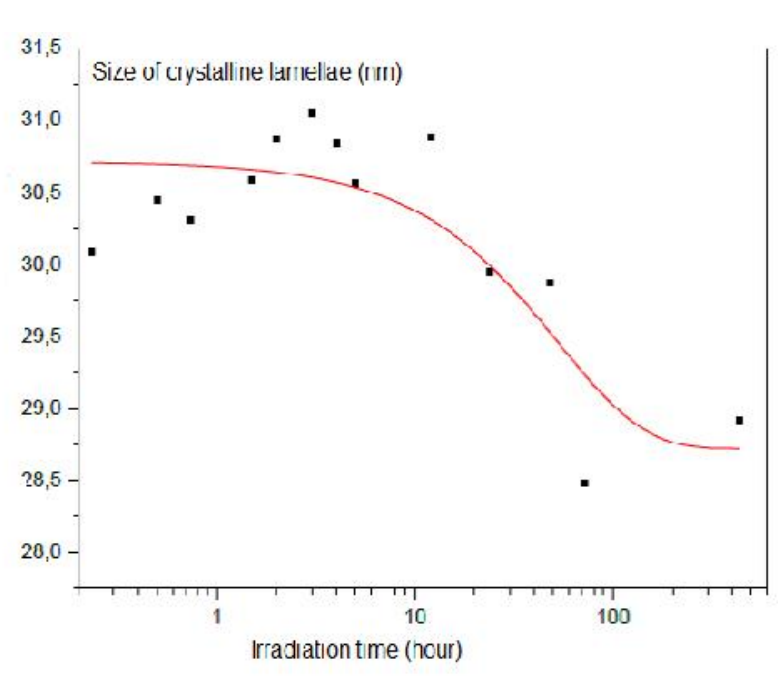

Fig.14. Evolution of the size of crystalline lamellae as a function of UV irradiation time.

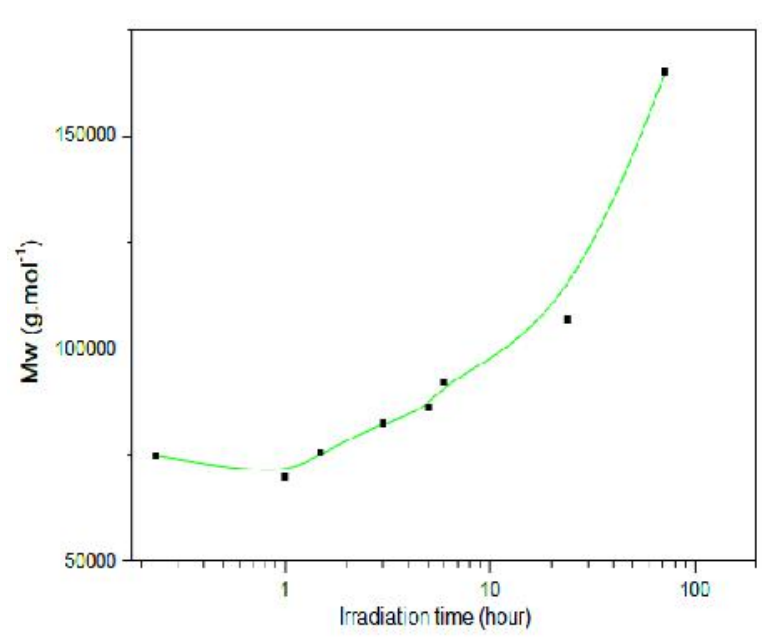

Fig.15. Evolution of the weight average molecular weight in the GEM PEHD $_{\text {as a }}$ function of UV irradiation time.

The use of different characterization techniques allowed concluding that oxidative chain cuts. One consequence is the fall of the molar mass of the GEM $_{\text {PEHD }}$ considered the criterion of end of life the most relevant for evaluating the lifespan of critical M'C GEM PEHD $_{\text {with defined }}$ molecular weight $100 \mathrm{~g} \cdot \mathrm{mol}^{-1}$. It showed a thermal oxidation of the top of the GEM $\mathrm{PEHD}$ from 18 days of aging by the presence of carbonyl compounds and the microstructural scale by increasing the degree of crystallinity due to a phenomenon of annealing and chimicristallisation. The results obtained by FTIR spectroscopy that highlight extraction in leachate carbonyl compounds of low molecular weight formed during the oxidation from the chains of $\mathrm{GEM}_{\mathrm{PEHD}}$ and that the activity of microorganisms on the surface of the GEM $\mathrm{PEHD}_{\mathrm{P}}$ is particularly higher than the oxidation state of the polymer is high. This important activity corresponding to a growth phase of the microorganisms is related to bioassimilation short chains of GEMPEHD carboxylated in leachate.

\section{CONCLUSION}

The results obtained show that the outlet temperature varies depending on the solar flux as well as geometric and climatic parameters. Among the main results, we quote:

- Large temperature value achieved in the summer solstice, which can reach $420 \mathrm{~K}$ in true solar noon. It mainly depends on the power consumption that is a function of the optical and 
geometrical parameters of the sensor. What say we leave this type of collector can favorably recommend in the water-heating sector.

- The temperature of the absorber is closest to $\mathrm{T}_{\mathrm{F}}$, which can be justified by its high absorptivity for visible solar radiation and a high emissivity for the infrared radiation of long wavelength with its coating. It is possible to keep the greater part of the incident solar energy and not lose as little heat by long wavelength radiation when the absorbent surface becomes hot. The glazing temperature is lower than that of $\mathrm{T}_{\mathrm{F}}$ when dependent optical, climatic, and specific parameters of the wind speed.

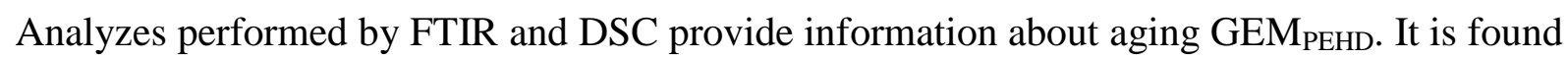
that thermal aging has an important influence on the volumetric strain due to increased crystallinity. The X-ray diffraction analysis showed the post crystallization phenomenon by revelation of the increased crystallinity of the aged sample. While FTIR analysis has shown that, this phenomenon is due only to the change in the structural morphology of the GEM

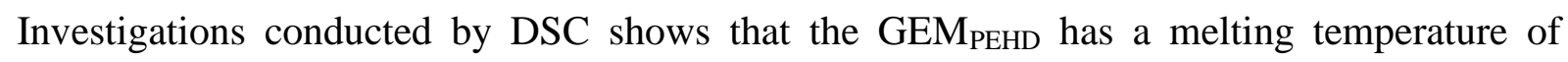
$131{ }^{\circ} \mathrm{C}$ for an aged sample while valley $135{ }^{\circ} \mathrm{C}$ for a blank sample characteristic of increasing the crystallinity of confirming the findings with the same further analyzes. Each analysis technique having its own sensitivity to this or that phenomenon, aggregation and correlation of all results obtained are essential for a comprehensive understanding of degradation mechanisms GEM $_{\mathrm{PEHD}}$. A question remains open on the choice of the molecule inserted into the GEM $M_{\text {PEHD }}$, this choice that can condition the type of information obtained. In our case, with Irganox B225, the results show a high sensitivity to rearrangements of the macromolecular chains of the GEM $_{\mathrm{PEHD}}$. An analysis according to a multiscale approach and by various characterization techniques resulted in the determination of a criterion of end of

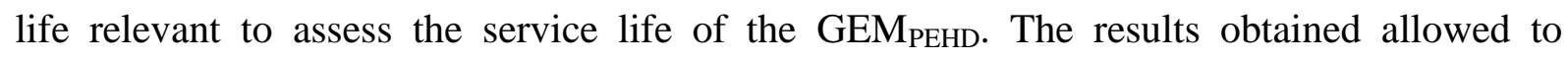
conclude embrittlement induced oxidation chains cuts the polymer, whose consequence is the

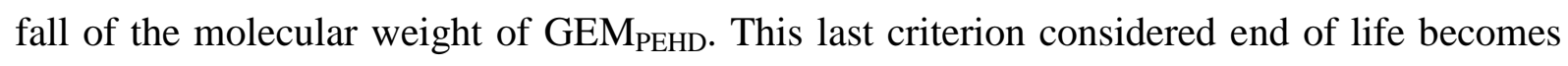
critical in the case of $\mathrm{GEM}_{\mathrm{PEHD}}$ below a value of $100 \mathrm{~g} \cdot \mathrm{mol}^{-1}$, which is equivalent to the molecular level at a concentration of carbonyl compounds in the order of $0.08 \mathrm{~mol}_{\mathrm{g}} \mathrm{g}^{-1}$. 


\section{REFERENCE}

[1] Bidart A, Dubois L. Les énergies fossiles et renouvelables. Dossier Pédagogique de la Fondation Polaire Internationale. 2003.

[2] OCDE. Énergie : les cinquante prochaines années. OECD Publishing. 2010.

[3] Castagnet L, Deburck Y. Relative influence of microstructure and macroscopic triaxiality on cavitation damage in semi-cristalline polymer. Material Science Engineering: A. 2007. 448, 56-66. http://dx.doi:10.1016/j.msea.2006.11.100

[4] Mkacher I. Vieillissement thermique des graines de PE et de PVC des câbles électriques. Thèse de Doctorat. Ecole nationale supérieure des arts et métiers de PARIS. 2012.

[5] Rowe R K, Sangam H P. Durability of HDPE géomembranes. Geotextiles and Geomembranes. 2012. 20. 77-95. http://dx.doi:10.1016/S0266-1144(02)00005-5

[6] Ministère de l'Energie et des Mines. Bilan énergétique nationale de l'année 2013. 2014.

[7] Grynning S, Goia F, Rognvik E, Time B. Possibilities for characterization of a PCM window system using large scale measurements. International Journal of Sustainable Built Environment. 2013. 2 (1). 56-64. http://dx.doi:10.1016/j.ijsbe.2013.09.003

[8] Schefflera T B, Leao A J. Fabrication of polymer film heat transfer elements for energy efficient multi-effect distillation. Desalination. 2008. 222. 696-710. http://dx.doi:10.1016/j.desal.2007.02.076

[9] Datcu S, Ibos L, Candau Y, Matteï S. Improvement of building wall surface temperature measurements by infrared thermography. Infrared Physics \& Technology. 2005.46 (6). 451-467. http://dx.doi:10.1016/j.infrared.2005.01.001

[10] Ibos L, Marchetti M, Boudenne A, Datcu S, Livet J, Candau Y. Infrared emissivity measurement device : Principle and applications. Measurement Science and Technology. 2006. 17. 2950-2956. http://dx.http://dx.doi.org/10.1088/0957-0233/17/11/013

[11] Marchetti M, Ibos L, Boudenne A, Datcu S, Candau Y, Dumoulin J, Livet J. Analyse du comportement radiatif de matériaux de l'infrastructure routière : Principes et mesures de l'émissivité infrarouge. Bulletin des Laboratoires des Ponts et Chaussées. 2008. 272. $45-55$. 
[12] Baba Ahmed N, Benmoussat A, Benouaz T, Mesures experimentales, analyse et modelisation de la dependance de l'emissivite en fonction de la temperature. Revue des sciences fondamentales et appliquées. 2010. 2 (1). 12-22. http://dx.doi.org/10.4314/jfas.v2i1.2

[13] Nicolazo C, Sarda A, Vachot P, Mousseau P, Deterre P. Change on temperature at the surface of injection moulded parts. Journal of Materials Processing Technology. 2010. 210 (2). 233-237. http://dx.doi:10.1016/j.jmatprotec.2009.09.005

[14] D’Antoni M, Onorio S. Massive Solar-Thermal Collectors: A critical literature review. Renewable and Sustainable Energy Reviews. 2012. 16. 3666-3679. http://dx.doi:10.1016/j.rser.2012.02.076

[15] Rani N, Setia H, Dutt M, Wanchoo R K. Natural Convection Heat Transfer from Inclined Cylinders: A Unified Correlation, International Journal of Mathematical. Computational, Physical, Electrical and Computer Engineering. 2014.8 (1). 100-105.

[16] Bjørn Holmedal. Stability of rolls in finite-amplitude Rayleigh-Bénard convection in a high-Prandtl-number fluid between a perfectly conducting boundary and a slab of finite thickness and finite conductivity. European Journal of Mechanics - B/Fluids. 2012. 34. 115-120. http://dx. doi:10.1016/j.euromechflu.2012.01.018

[17] Tari I. Natural convection simulations and numerical determination of critical tilt angles for a parallel plate channel. Energy conversion and management. 2010. 51. 685-695. http://dx.doi:10.1016/j.enconman.2009.11.012

[18] Benmoussat A, Baba Ahmed N, Ainad-tabet S, Belahcene B. Study on the energetic parameters in a photothermic sensor with black polymeric film. Revue des sciences fondamentales et appliquées. 2010. 2 (1). 1-11. http://dx.doi.org/10.4314/jfas.v2i1.1

[19] Alvarado R, Xamán J, Hinojosa J, Álvarez G. Interaction between natural convection and surface thermal radiation in tilted slender cavities. International Journal of thermal sciences. 2008. 47. 355-368. http://dx.doi:10.1016/j.ijthermalsci.2007.03.007

[20] Juanico L, Dilalla N. The pulsed-flow design: A new low-cost solar collector. Renewable Energy. 2016. 87. 422-429. http://dx.doi:10.1016/j.renene.2015.10.042

[21] Rowe R K, Rimal S, Sangam H. Ageing of HDPE geomembrane exposed to air, water 
and leachate at different temperatures. Geotextiles and Geomembranes. 2009. 27. 137-151. http://dx.doi:10.1016/j.geotexmem.2008.09.007

[22] Fady B A, Rowe R K. Effect of high temperatures on antioxidant depletion from different HDPE géomembranes. Geotextiles and Geomembranes. 2014. 42. 284-301. http://dx.doi:10.1016/j.geotexmem.2014.05.002

[23] Yang R and al. Effects of inorganic fillers on the natural photo-oxidation of high-density polyethylene. Polymer Degradation and Stability. 2005. 88 (2). 333-340. http://dx.doi:10.1016/j.polymdegradstab.2004.11.011

[24] Ewais A M R, Rowe R K. Effect of aging on the stress crack resistance of an HDPE geomembrane. Polymer Degradation and Stability. 2014. 109. 194-208. http://dx.doi:10.1016/j.polymdegradstab.2014.06.013

[25] Guadagno L and al. Chemical and morphologial modifications of irradiated linear low-density polyethylene. Polymer Degradation and Stability. 2001.72 (1). 175-186. http://dx.doi:10.1016/S0141-3910(01)00024-6

[26] Craig I H. and al. Photo-induced scission and crosslinking in LDPE, LLDPE, and HDPE. Polymer Engineering and Science. 2005.45 (4). 579-587. http://dx.DOI: 10.1002/pen.20313

\section{How to cite this article:}

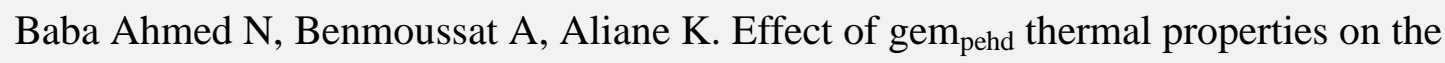
propagation of heat in solar stills. J. Fundam. Appl. Sci., 2016, 8(3), 712-730. 